\title{
OPTIMAL CLOSED-LOOP OPERATION OF BINARY BATCH DISTILLATION COLUMNS
}

\author{
Jesus Alvarez*, Eduardo Castellanos-Sahagún, Carlos Fernández, and Salvador Aguirre \\ Universidad Autónoma Metropolitana \\ Departamento de Ingeniería de Procesos e Hidráulica \\ Apdo. Postal 55534, 09340, México D.F., México \\ *Corresponding author: e-mail: jac@xanum.uam.mx ; Fax: +52 (55) 58044900
}

\begin{abstract}
The problem of designing an on-line optimizing robust output-feedback (OF) controller for binary batch distillation columns with temperature measurements is addressed. The combination of optimality, passivity and detectability notions leads to an estimator-based material balance controller that, for an ample range of load compositions maximizes the profit and yields the prespecified product purity. The scheme has: (i) a criterion to choose the sensor number and locations, (ii) an event controller that decides the total reflux, start-up and partial reflux withdrawal periods, and (iii) a tracking controller that steers the batch distillation column motion along an on-line optimized path. The approach is applied to a previously studied example. Copyright (C) 2005 IFAC.
\end{abstract}

Keywords: Distillation columns, batch control, material balance control, chemical variables control, optimal control, estimators.

\section{INTRODUCTION}

In the distillation process engineering field, it is known that batch columns offer advantages over the continuous ones, and that the transient nonlinear nature of batch columns gives rise to complex operation and control design problems (Muhrer et. al, 1992). Basically, the operation and control problems have been addressed in sequential manner. First, the operation is designed via open-loop optimization (Mujtaba et. al, 1996), yielding a nominal output signal to be followed by means of a feedback control that is designed in a second stage, using either linear gain scheduled (Finefrock et. al, 1994), nonlinear model predictive (Bosley et. al, 1992), geometric (Barolo et. al, 1998) or adaptive (Li et. al, 2001) techniques. Recently, it has been proposed an approach for the simultaneous consideration of the batch operation and control design problems, by looking at the notions of stability, output controllability, passivity and detectability that underlie both problems (Alvarez et. al, 2004b). The approach has been applied to a semi-batch emulsion polymerization reactor (Alvarez et. al, 2004b), and to the nominal study of a binary batch distillation column without hydraulic dynamics, fixed load composition, and noiseless measurements (Alvarez et. al, 2004a). Even though the last study established the nominal solvability of the problem, its applicability requires the further consideration of robustness-oriented issues which are addressed in the present work: the behavior of the controller in the presence of measurement noise, high-frequency hydraulic dynamics, and load composition disturbances, as well as the choice of number and location of sensors. However, it is known that in distillation columns, hydraulic dynamics and measurement noise limit the control behavior (Castellanos et. al, 2005b), especially in high-purity columns, and these considerations motivate the present robustness oriented study.

In this work, the problem of designing an optimizing robust feedback controller for binary batch distillation columns with temperature measurements is addressed, including the choices of sensor number and locations. The combination of optimality, passivity and detectability notions leads to an estimator-based material balance controller that, for an ample range of load compositions maximizes the profit and yields the product purity within specifications. The sensor number and location choices follow from a nonlinear detectability analysis with testing via estimator implementation. The control scheme has a simple tuning scheme coupled with a batch motion stability criterion. The approach is applied to an early studied simulated example (Barolo et. al, 1998; Alvarez et. al, 2004a).

\section{CONTROL PROBLEM}

Consider the N-tray binary batch distillation column depicted in Fig. 1, with reboiler, condenser and an accumulator vessel to collect the distillate product. $\mathrm{c}_{\mathrm{F}}$ varies within the interval $\mathrm{C}_{\mathrm{F}}=\left[\mathrm{c}_{\mathrm{F}}^{-}, \mathrm{c}_{\mathrm{F}}^{+}\right]$, there are $\mathrm{n}_{\mathrm{T}}$ temperature measurements whose number and locations $\left(\mathrm{s}_{1}, \ldots, \mathrm{s}_{\mathrm{nT}}\right)$ are to be determined. At time $\mathrm{t}=$ 0 , a mixture of $m_{L}$ moles with composition $c_{F}$ is 
loaded. In its startup period $\left[0, \mathrm{t}_{\mathrm{s}}\right]$, the column is operated at total reflux (molar) rate $\mathrm{R}=\mathrm{V}$, until the

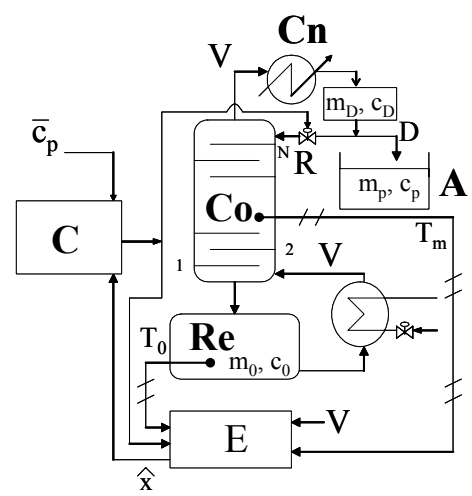

Fig. 1. Batch distillation column and control system: accumulator (A), condenser $(\mathrm{Cn})$, column (Co), controller (C), estimator (E), reboiler (Re), control $(\mathrm{u}=\mathrm{R})$, and measurement $\left[\mathrm{y}=\left(\mathrm{T}_{0}, . ., \mathrm{T}_{\mathrm{m}}\right)^{\prime}\right]$

time $t_{s}$ when the distillate composition $c_{D}(t)$ reaches the prescribed product value $\overline{\mathrm{c}}_{\mathrm{p}}$. Then, $\mathrm{c}_{\mathrm{D}}(\mathrm{t})=\overline{\mathrm{c}}_{\mathrm{p}}$, is maintained by manipulating $\mathrm{R}$ and withdrawing distillate at a time-varying rate $(\mathrm{V}-\mathrm{R})$, until a given utility function, say

$\mathrm{J}(\mathrm{t})=\left[\mathrm{C}_{\mathrm{p}} \mathrm{m}_{\mathrm{p}}(\mathrm{t})-\mathrm{C}_{\mathrm{L}} \mathrm{m}_{\mathrm{L}}-\mathrm{C}_{\mathrm{h}} \lambda_{\mathrm{V}} \int_{\mathrm{o}}^{\mathrm{t}} \mathrm{V}(\tau) \mathrm{d} \tau\right.$

$$
\left.-C_{c} \lambda_{R} \int_{0}^{t} R(\tau) d \tau\right] /\left(t+t_{d}\right)-C_{O}, t \geq t_{s}, j\left(t_{f}\right)=0
$$

reaches its maximum value at time $t_{f}$. $J$ is the utility (\$) per unit time, $\mathrm{m}_{\mathrm{p}}$ are the moles of collected product in the accumulator, $\mathrm{C}_{\mathrm{p}}\left(\right.$ or $\left.\mathrm{C}_{\mathrm{L}}\right)$ is the product (or load) value per mole, $\mathrm{C}_{\mathrm{h}}$ (or $\mathrm{C}_{\mathrm{c}}$ ) is the heating (or cooling) cost per heat unit, $\mathrm{C}_{\mathrm{O}}$ is the operation cost per unit time, $t_{d}$ is the dead time between batches, and $\lambda_{V}$ (or $\left.\lambda_{R}\right)$ is the approximated heat of vaporization (or condensation) in the reboiler (or condenser). Under standard assumptions, the composition and holdup dynamics are described by the nonlinear differential equation set (Muhrer et. al, 1992):

$$
\begin{aligned}
& \dot{\mathrm{c}}_{0}=\left\{\mathrm{R}\left(\mathrm{c}_{1}-\mathrm{c}_{0}\right)-\mathrm{V}\left[\mathrm{E}\left(\mathrm{c}_{0}\right)-\mathrm{c}_{0}\right]\right\} / \mathrm{m}_{0}:=\mathrm{f}_{0}^{\mathrm{c}}, \quad 0 \leq \mathrm{t} \leq \mathrm{t}_{\mathrm{f}} \\
& \dot{\mathrm{c}}_{\mathrm{i}}=\left\{\mathrm{R}\left(\mathrm{c}_{\mathrm{i}+1}-\mathrm{c}_{\mathrm{i}}\right)-\mathrm{V}\left[\mathrm{E}\left(\mathrm{c}_{\mathrm{i}}\right)-\mathrm{E}\left(\mathrm{c}_{\mathrm{i}-1}\right)\right]\right\} / \mathrm{m}_{\mathrm{i}}:=\mathrm{f}_{\mathrm{i}}^{\mathrm{c}}, 1 \leq \mathrm{i} \leq \mathrm{N}-1 \\
& \dot{\mathrm{c}}_{\mathrm{N}}=\left\{\mathrm{R}\left(\mathrm{c}_{\mathrm{D}}-\mathrm{c}_{\mathrm{N}}\right)-\mathrm{V}\left[\mathrm{E}\left(\mathrm{c}_{\mathrm{N}}\right)-\mathrm{E}\left(\mathrm{c}_{\mathrm{N}-1}\right)\right]\right\} / \mathrm{m}_{\mathrm{N}}:=\mathrm{f}_{\mathrm{N}}^{\mathrm{c}} \\
& \dot{\mathrm{c}}_{\mathrm{D}}=0 \text { if } \mathrm{t} \leq \mathrm{t}_{\mathrm{s}} \text {, or } \mathrm{V}\left[\mathrm{E}\left(\mathrm{c}_{\mathrm{N}}\right)-\mathrm{c}_{\mathrm{D}}\right] / \mathrm{m}_{\mathrm{D}}:=\mathrm{f}_{\mathrm{D}}^{\mathrm{c}}, \mathrm{t}>\mathrm{t}_{\mathrm{s}} \\
& \dot{\mathrm{c}}_{\mathrm{P}}=0 \text { if } \mathrm{t} \leq \mathrm{t}_{\mathrm{s}} \text { or }(\mathrm{V}-\mathrm{R})\left(\mathrm{c}_{\mathrm{D}}-\mathrm{c}_{\mathrm{P}}\right) / \mathrm{m}_{\mathrm{P}}:=\mathrm{f}_{\mathrm{p}}^{\mathrm{c}}, \mathrm{t}>\mathrm{t}_{\mathrm{s}} \\
& c_{p}\left(t_{0}\right)=0, c_{p}\left(t_{s}\right)=c_{D}\left(t_{s}\right) \\
& {\left[\mathrm{c}_{0}(0), \mathrm{c}_{1}(0), \ldots, \mathrm{c}_{\mathrm{N}}(0), \mathrm{c}_{\mathrm{D}}(0)\right]^{\prime}=\mathrm{c}_{\mathrm{F}}(1, \ldots, 1)^{\prime}} \\
& \mathrm{c}_{\mathrm{F}} \in\left[\mathrm{c}_{\mathrm{F}}^{-}, \mathrm{c}_{\mathrm{F}}^{+}\right]:=\mathrm{C}_{\mathrm{F}} \\
& \dot{\mathrm{m}}_{0}=\mathrm{R}-\mathrm{V}:=\mathrm{f}_{0}^{\mathrm{m}}, \quad \quad \mathrm{m}_{0}(0)=\mathrm{m}_{\mathrm{L}} \\
& \dot{\mathrm{m}}_{\mathrm{i}}=\mathrm{L}\left(\mathrm{m}_{\mathrm{i}+1}\right)-\mathrm{L}\left(\mathrm{m}_{\mathrm{i}}\right), \quad \mathrm{L}\left(\mathrm{m}_{\mathrm{i}}\right)=\mathrm{a}+\left(\mathrm{m}_{\mathrm{i}}-\mathrm{b}\right) \lambda_{\mathrm{m}}:=\mathrm{f}_{\mathrm{i}}^{\mathrm{m}} \\
& \mathrm{m}_{\mathrm{i}}(0)=\mathrm{m}_{\mathrm{io}}, \quad 1 \leq \mathrm{i} \leq \mathrm{N} \\
& \dot{\mathrm{m}}_{\mathrm{p}}=0, \mathrm{t} \leq \mathrm{t}_{\mathrm{s}} \text { or } \mathrm{V}-\mathrm{R}:=\mathrm{f}_{\mathrm{p}}^{\mathrm{m}}, \mathrm{t}>\mathrm{t}_{\mathrm{s}} \text {, } \\
& \mathrm{m}_{\mathrm{p}}\left(\mathrm{t}_{0}\right)=0, \mathrm{~m}_{\mathrm{p}}\left(\mathrm{t}_{\mathrm{s}}\right)=0 \\
& \dot{J}=\left[-J+C_{p}(V-R)-C_{h} \lambda_{V} V-C_{c} \lambda_{R} R\right] /\left(t+t_{d}\right):=f_{J} \\
& \mathrm{~J}_{\mathrm{o}}=-\left(\mathrm{C}_{\mathrm{L}} \mathrm{m}_{\mathrm{L}} / \mathrm{t}_{\mathrm{d}}+\mathrm{C}_{\mathrm{O}}\right) \\
& \mathrm{y}_{\mathrm{i}}=\beta\left(\mathrm{c}_{\mathrm{i}}\right)=\mathrm{T}_{\mathrm{i}}, \quad \mathrm{i}=\mathrm{s}_{1}, \ldots, \mathrm{s}_{\mathrm{n}_{\mathrm{T}}} \text {; } \\
& \mathrm{R}=\mathrm{V}, 0 \leq \mathrm{t} \leq \mathrm{t}_{\mathrm{s}} ; \mathrm{R} \leq \mathrm{V} \mathrm{t}_{\mathrm{s}}<\mathrm{t} \leq \mathrm{t}_{\mathrm{f}}
\end{aligned}
$$

where $c_{i}$ is the light component mole fraction at the ith stage, $\mathrm{T}_{\mathrm{i}}$ is the temperature at the $\mathrm{s}_{\mathrm{i}}$-th tray, $\mathrm{m}_{0}$ (or $\mathrm{m}_{\mathrm{p}}$ ) is the boiler or product vessel molar holdup, $\mathrm{L}$ is the hydraulic function dependency on the tray holdup, $\mathrm{E}$ and $\beta$ are respectively the nonlinear liquidvapor equilibrium and bubble-point functions, and $\lambda_{\mathrm{m}}$ is the individual tray characteristic frequency, $\mathrm{n}_{\mathrm{T}}$ is the number of temperature sensors and $\mathrm{s}_{\mathrm{n}_{1}}, \ldots, \mathrm{s}_{\mathrm{n}_{\mathrm{T}}}$ are their locations.

Since the hydraulic dynamics are considerably (thirty to one hundred times) faster than the composition dynamics, the control model must assume that the hydraulic dynamics are in quasi-static regime according to the boundary layer stable dynamics:

$\dot{\tilde{m}}_{i}=-\lambda_{m}\left(\widetilde{m}_{i}-\widetilde{m}_{i+1}\right)-\dot{R}(t) / \lambda_{m}$,

$\widetilde{\mathrm{m}}_{\mathrm{i}}=\mathrm{m}_{\mathrm{i}}-\mathrm{m}_{\mathrm{i}}^{*}(\mathrm{t}), \mathrm{m}_{\mathrm{i}}^{*}(\mathrm{t}) \approx[\mathrm{R}(\mathrm{t})-\mathrm{a}] / \lambda_{\mathrm{m}}+\mathrm{b}, 1 \leq \mathrm{i} \leq \mathrm{N}$

where $\widetilde{m}_{i}$ is the holdup $m_{i}$ minus its quasi-static timevarying value $\mathrm{m}_{\mathrm{i}}^{*}(\mathrm{t})$. in singularly perturbed (SP) form (Khalil, 2002), the column full dynamics is written as follows:

$$
\begin{aligned}
& \dot{\mathrm{x}}=\mathrm{f}\left(\mathrm{x}, \mathrm{u}_{\mathrm{R}}, \mathrm{t}\right)+\mathrm{q}_{\mathrm{x}}\left(\mathrm{x}, \mathrm{u}_{\mathrm{R}}, \mathrm{t} ; \widetilde{\mathrm{m}}\right), \mathrm{y}=\mathrm{h}(\mathrm{x})+\mathrm{q}_{\mathrm{y}}(\mathrm{x} ; \widetilde{\mathrm{x}})(3) \\
& \mathrm{u}_{\mathrm{e}}=\left(\mathrm{t}_{\mathrm{s}}, \mathrm{t}_{\mathrm{f}}\right)^{\prime}, \quad \mathrm{x}(0)=\mathrm{x}_{\mathrm{o}}, 0 \leq \mathrm{t} \leq \mathrm{t}_{\mathrm{f}} \\
& \dot{\mathrm{m}}_{\mathrm{i}}=-\lambda_{\mathrm{m}}\left(\widetilde{\mathrm{m}}_{\mathrm{i}}-\widetilde{\mathrm{m}}_{\mathrm{i}+1}\right)-\dot{\mathrm{R}}(\mathrm{t}) / \lambda_{\mathrm{m}} \\
& \quad \widetilde{\mathrm{m}}_{\mathrm{i}}\left(\mathrm{t}_{\mathrm{o}}\right)=\widetilde{\mathrm{m}}_{\mathrm{io},}, 1 \leq \mathrm{i} \leq \mathrm{N}, \widetilde{\mathrm{m}}=\left(\widetilde{\mathrm{m}}_{1}, \ldots, \widetilde{\mathrm{m}}_{\mathrm{N}}\right)^{\prime} \\
& \dot{\widetilde{\mathrm{x}}}=\mathrm{q}_{\mathrm{x}}\left(\mathrm{x}, \mathrm{u}_{\mathrm{R}}, \mathrm{t} ; \widetilde{\mathrm{m}}\right), \quad \widetilde{\mathrm{x}}\left(\mathrm{t}_{\mathrm{o}}\right)=\widetilde{\mathrm{x}}_{\mathrm{o}} \\
& \mathrm{q}_{\mathrm{x}}\left(\mathrm{x}, \mathrm{u}_{\mathrm{R}}, \mathrm{t} ; 0\right)=0, \quad \mathrm{q}_{\mathrm{y}}\left(\mathrm{x}, \mathrm{u}_{\mathrm{R}}, \mathrm{t} ; 0\right)=0 \\
& \text { where } \\
& \mathrm{x}=\left(\mathrm{c}_{0}, \ldots, \mathrm{c}_{\mathrm{N}}, \mathrm{c}_{\mathrm{D}}, \mathrm{c}_{\mathrm{P}}, \mathrm{m}_{0}, \mathrm{~m}_{\mathrm{P}}, \mathrm{J}\right)^{\prime}, \\
& \mathrm{u}_{\mathrm{R}}=\mathrm{R}, \quad \mathrm{u}_{\mathrm{e}}=\left(\mathrm{t}_{\mathrm{s}}, \mathrm{t}_{\mathrm{f}}\right)^{\prime}, \quad \mathrm{y}=\left(\mathrm{y}_{1}, \ldots, \mathrm{y}_{\mathrm{n}_{\mathrm{T}}}\right)^{\prime} \\
& \mathrm{x}_{\mathrm{o}}=\left[\mathrm{c}_{\mathrm{L}}(1, \ldots, 1,1)^{\prime}, 0, \mathrm{~m}_{\mathrm{L}}, 0, \mathrm{~J}_{\mathrm{o}}\right]^{\prime}:=\mathrm{f}_{\mathrm{o}}\left(\mathrm{c}_{\mathrm{L}}, \mathrm{m}_{\mathrm{L}}, \mathrm{J}_{\mathrm{o}}\right) \\
& \mathrm{h}(\mathrm{x})=\left[\beta\left(\mathrm{c}_{\mathrm{s}_{1}}\right), \ldots, \beta\left(\mathrm{c}_{\mathrm{s}_{\mathrm{rT}}}\right)\right]
\end{aligned}
$$

The term $\mathrm{q}_{\mathrm{x}}$ (or $\mathrm{q}_{\mathrm{y}}$ ) accounts for the effective process (or measurement) noise, $u_{R}$ over $\left(t_{s}, t_{f}\right]$ is the feedback control input, and $u_{\mathrm{e}}$ is the feedback event control input which sets the total reflux-to-extraction regime switching time $t_{s}$ as well as the batch duration $t_{f}$. Given the objective function $J(1)$, the prescribed product composition $\overline{\mathrm{c}}_{\mathrm{P}}$, the load composition variation interval $C_{L}$, and the column reduced model [Eq. (3) with $\widetilde{\mathrm{m}}=0$ and $\widetilde{\mathrm{x}}=0$ ]

$$
\begin{array}{lll}
\dot{x}=f\left(x, u_{R}, t\right), & y=h(x), & \operatorname{dim}(x)=n \\
u_{e}=\left(t_{s}, t_{f}\right)^{\prime}, & x(0)=x_{0}, & 0 \leq t \leq t_{f}
\end{array}
$$

our problem consists in designing a dynamic robust (i.e., passive) OF controller

$$
\begin{array}{rlr}
\dot{x}_{\mathrm{c}}= & \mathrm{f}_{\mathrm{c}}\left[\mathrm{x}_{\mathrm{c}}, \mathrm{y}(\mathrm{t})\right], & \mathrm{x}_{\mathrm{c}}\left(\mathrm{t}_{\mathrm{o}}\right)=\mathrm{x}_{\mathrm{co}}, \\
\mathrm{t} \in\left[\mathrm{t}_{\mathrm{o}}, \mathrm{t}_{\mathrm{f}}\right], \mathrm{t}_{\mathrm{s}}=\mu_{\mathrm{s}}\left(\mathrm{x}_{\mathrm{c}}\right), & \mathrm{t}_{\mathrm{f}}=\mu_{\mathrm{f}}\left(\mathrm{x}_{\mathrm{c}}\right) \\
\mathrm{u}=\mu\left(\mathrm{x}_{\mathrm{c}}\right): \mathrm{u}=\mathrm{V}, \mathrm{t}_{\mathrm{o}} \leq \mathrm{t} \leq \mathrm{t}_{\mathrm{s}} ; & \mathrm{u}=\mu_{\mathrm{R}}\left(\mathrm{x}_{\mathrm{c}}\right), \mathrm{t}_{\mathrm{s}}<\mathrm{t} \leq \mathrm{t}_{\mathrm{f}}
\end{array}
$$

so that for any load concentration $\mathrm{c}_{\mathrm{F}} \in \mathrm{C}_{\mathrm{F}}$ :

(i) the utility function $\mathrm{J}$ is maximum at $t_{\mathrm{f}}$ :

(ii) the product composition is at its nominal value (iii) sensor number and locations (S) must be found

$$
\begin{array}{ll}
\dot{\mathrm{J}}\left(\mathrm{t}_{\mathrm{f}}\right)=0, & \mathrm{c}_{\mathrm{P}}\left(\mathrm{t}_{\mathrm{f}}\right)=\overline{\mathrm{c}}_{\mathrm{P}}, \quad \dot{\mathrm{c}}_{\mathrm{P}}\left(\mathrm{t}_{\mathrm{f}}\right)=0, \\
\mathrm{n}_{\mathrm{T}}=\operatorname{dim}(\mathrm{y}), & \mathrm{S}=\left(\mathrm{s}_{\mathrm{n}_{1}}, \ldots, \mathrm{s}_{\mathrm{n}_{\mathrm{T}}}\right)
\end{array}
$$




\section{OPTIMAL STATE-FEEDBACK CONTROL}

Having as point of departure a previous study on the nominal version of the same batch column control problem (Alvarez et. al, 2004a), here are included three additional considerations: (i) the event control, (ii) a feedforward (FF) material balance controller is employed instead of a state-feedback (SF) one, and (iii) the presence of the parasitic hydraulic dynamics is accounted for in the dynamical behavior assessment.

\subsection{Stability}

Since a batch column is described by the finite-time motion $\mathrm{x}(\mathrm{t})$ (3) or solution of a non-autonomous dynamical system (2), the standard definitions of asymptotic stability of critical points, which are appropriate for continuous processes, cannot be formally applied to the batch case, and the same is true for the controllability and detectability properties. In a batch process these definitions apply to one particular motion, and the motion deviations, caused by initial state and exogenous input disturbances, exhibit accumulation or irreversibility features. If admissible disturbances produce admissible motion deviations, the related motion is regarded stable in the so-called practical stability sense (La Salle and Lefschetz, 1961), and some outputs may exhibit growing or decreasing deviations, depending on the particular system. These notions of input-state and input-output stability-type are presented next in technical form (Alvarez et. al, 2004a).

Definition 1. The batch motion

$\mathrm{x}(\mathrm{t})=\tau\left[\mathrm{t}, \mathrm{t}_{\mathrm{o}}, \mathrm{x}_{\mathrm{o}}, \mathrm{u}(\cdot)\right]$

of the nonlinear system

$\dot{x}=f[x, u(t), t], x\left(t_{0}\right)=0, \quad z=h(x)$

is $\mathrm{P}$ (practically)-stable if, for given disturbance sizes $\varepsilon_{\mathrm{o}}, \varepsilon_{\mathrm{u}}, \varepsilon_{\mathrm{x}}>0$ and final time $\mathrm{t}_{\mathrm{f}}$, the perturbed motions $\hat{\mathrm{x}}$ $(t)=x(t)+\widetilde{x}(t)$ are bounded as follows:

$\left|\widetilde{\mathrm{x}}_{\mathrm{o}}\right| \leq \varepsilon_{\mathrm{o}}, \quad|\widetilde{\mathrm{u}}(\mathrm{t})| \leq \varepsilon_{\mathrm{u}}, \Rightarrow$

$|\widetilde{\mathrm{x}}(\mathrm{t})| \leq \mathrm{ae}^{\lambda(\mathrm{t}-\mathrm{to})}\left|\widetilde{\mathrm{x}}_{\mathrm{o}}\right|+\mathrm{a}_{\mathrm{t}_{\mathrm{o}}}^{\mathrm{t}} \mathrm{e}^{\lambda(\mathrm{t}-\tau)}[\mathrm{b}|\widetilde{\mathrm{u}}(\tau)|] \mathrm{d} \tau \leq \varepsilon_{\mathrm{x}}$

The related output trajectory $\mathrm{z}(\mathrm{t})=\mathrm{h}[\mathrm{x}(\mathrm{t})]$ is $\mathrm{P}^{+}\left(\right.$or $\left.\mathrm{P}^{-}\right)$ stable if the perturbed outputs are bounded as follows, with $\gamma \geq 0$ (or $\gamma<0$ ):

$|\widetilde{\mathrm{z}}(\mathrm{t})| \leq \alpha \mathrm{e}^{\gamma(\mathrm{t}-\mathrm{to})}\left|\widetilde{\mathrm{x}}_{\mathrm{o}}\right|+\alpha \int_{\mathrm{t}_{\mathrm{o}}}^{\mathrm{t}} \mathrm{e}^{\gamma(\mathrm{t}-\mathrm{to}))}[\beta|\widetilde{\mathrm{u}}(\tau)|] \mathrm{d} \tau \leq \varepsilon_{\mathrm{z}}$

These definitions of state motion and output stability (Sontag, 2000) are necessary to address the key issues of output tracking with state stability and estimator convergence in batch processes.

\subsection{State-feedback control}

Assume that the optimal SF controller (5) does exist, enforce the initial $\left(t_{0}\right)$, intermediate $\left(t_{s}\right)$ and terminal $\left(t_{f}\right)$ conditions (4) and restrictions (6). From passivity arguments it follows that the N-th tray composition must be the tracked output over the withdrawal period, this is:
$\mathrm{z}(\mathrm{t})=\overline{\mathrm{c}}_{\mathrm{N}}=\mathrm{E}^{-1}\left(\overline{\mathrm{c}}_{\mathrm{p}}\right):=\overline{\mathrm{z}}, \quad \mathrm{t}_{\mathrm{s}} \leq \mathrm{t} \leq \mathrm{t}_{\mathrm{f}}$

leading to the event SF and material balance-based passive tracking controllers:

$\mathrm{u}=\mathrm{V}, \quad \mathrm{t}_{\mathrm{o}} \leq \mathrm{t} \leq \mathrm{t}_{\mathrm{s}}=\mu_{\mathrm{s}}\left(\mathrm{c}_{\mathrm{N}}, \overline{\mathrm{c}}_{\mathrm{p}}\right)$

$\mathrm{u}=\mu_{\mathrm{R}}\left(\mathrm{x}, \overline{\mathrm{c}}_{\mathrm{p}}\right), \mathrm{t}_{\mathrm{s}}<\mathrm{t} \leq \mathrm{t}_{\mathrm{f}}=\mu_{\mathrm{f}}\left(\mathrm{c}_{\mathrm{p}}, \mathrm{c}_{\mathrm{N}-1}, \mathrm{~m}_{\mathrm{p}}, \mathrm{J}, \overline{\mathrm{c}}_{\mathrm{p}}\right)$

where

$\mu_{\mathrm{s}}\left(\mathrm{c}_{\mathrm{N}}, \overline{\mathrm{c}}_{\mathrm{p}}\right)=\left\{\mathrm{t} \in\left[0, \mathrm{t}_{\mathrm{f}}\right] \mid \mathrm{c}_{\mathrm{N}}(\mathrm{t})=\mathrm{E}^{-1}\left(\overline{\mathrm{c}}_{\mathrm{p}}\right)\right\}=\mathrm{t}_{\mathrm{s}}$

$\mu_{\mathrm{f}}\left(\mathrm{c}_{\mathrm{D}}, \mathrm{c}_{\mathrm{N}-1}, \mathrm{~m}_{\mathrm{p}}, \mathrm{J}, \overline{\mathrm{c}}_{\mathrm{p}}\right)=$

$\left\{\mathrm{t} \in\left[\mathrm{t}_{\mathrm{s}}, \infty\right) \mid \mathrm{f}_{\mathrm{J}}\left[\mathrm{J}(\mathrm{t}), \mu[\mathrm{x}(\mathrm{t})], \mathrm{m}_{\mathrm{p}}(\mathrm{t}), \mathrm{t}\right]=0\right\}=\mathrm{t}_{\mathrm{f}}$

$\mathrm{u}=\mu_{\mathrm{R}}\left(\mathrm{c}_{\mathrm{D}}, \mathrm{c}_{\mathrm{N}-1}, \overline{\mathrm{c}}_{\mathrm{p}}\right)$ :

$\mu_{\mathrm{R}}\left(\mathrm{c}_{\mathrm{D}}, \mathrm{c}_{\mathrm{N}-1}, \overline{\mathrm{c}}_{\mathrm{p}}\right)=\mathrm{V}\left[\mathrm{E}\left(\overline{\mathrm{c}}_{\mathrm{N}}\right)-\mathrm{E}\left(\mathrm{c}_{\mathrm{N}-1}\right)\right] /\left[\left(\mathrm{c}_{\mathrm{D}}-\overline{\mathrm{c}}_{\mathrm{N}}\right)\right]:=\mu_{\mathrm{R}}\left(\mathrm{x}, \overline{\mathrm{c}}_{\mathrm{p}}\right)$

Comparing with the nonlinear controller forms

$\mu_{\mathrm{R}}\left(\mathrm{c}_{\mathrm{D}}, \mathrm{c}_{\mathrm{N}-1}, \mathrm{c}_{\mathrm{p}}\right)=\left\{\mathrm{V}^{+}\left[\mathrm{E}\left(\mathrm{c}_{\mathrm{N}}\right)-\mathrm{E}\left(\mathrm{c}_{\mathrm{N}-1}\right)\right]+\mu_{\mathrm{c}}\left(\mathrm{c}_{\mathrm{N}}, \overline{\mathrm{c}}_{\mathrm{p}}\right)\left(\mathrm{a}-\mathrm{b} \lambda_{\mathrm{m}}\right)\right.$

\}$/\left[\left(\mathrm{c}_{\mathrm{D}}-\mathrm{c}_{\mathrm{N}}\right)+\mu_{\mathrm{c}}\left(\mathrm{c}_{\mathrm{N}}, \overline{\mathrm{c}}_{\mathrm{p}}\right)\right]$

$\mu_{\mathrm{c}}\left(\mathrm{c}_{\mathrm{N}}, \overline{\mathrm{c}}_{\mathrm{p}}\right)=\left(\mathrm{k}_{\mathrm{c}} / \lambda_{\mathrm{m}}\right)\left(\mathrm{c}_{\mathrm{N}}-\overline{\mathrm{c}}_{\mathrm{N}}\right)$

employed before (Barolo et. al, 1998; Alvarez et. al, 2004a), in controller (8), the N-th tray composition is fixed, the SF term $\mu_{c}\left(c_{N}\right)$ is not included because there is no measurement at the $\mathrm{N}$-th tray. The corresponding (n-1)-dimensional zero-dynamics are given by

$\dot{x}=f\left[x, \mu_{R}\left(x, \bar{c}_{p}\right)\right], \quad x\left(t_{0}\right)=x_{0}, \quad t \in\left[t_{0}, t_{f}\right]$

$\mu_{\mathrm{s}}(\mathrm{x})=\mathrm{t}_{\mathrm{s}}<\mathrm{t} \leq \mathrm{t}_{\mathrm{f}}=\mu_{\mathrm{f}}(\mathrm{x}), \quad \mathrm{c}_{\mathrm{N}}\left(\mathrm{t}_{\mathrm{s}}\right)=\overline{\mathrm{c}}_{\mathrm{N}}=\mathrm{E}^{-1}\left(\overline{\mathrm{c}}_{\mathrm{p}}\right)$,

$\mathrm{x}=\left[\mathrm{c}_{0}, \ldots, \mathrm{c}_{\mathrm{N}-1}, \mathrm{c}_{\mathrm{D}}, \mathrm{c}_{\mathrm{P}}, \mathrm{m}_{0}, \mathrm{~m}_{\mathrm{P}}, \mathrm{J}\right]^{\prime}$

and their unique solution motion is

$\mathrm{x}(\mathrm{t})=\tau_{\mathrm{I}}\left(\mathrm{t}, \mathrm{t}_{\mathrm{o}}, \mathrm{c}_{\mathrm{F}}, \mathrm{m}_{0}, \overline{\mathrm{c}}_{\mathrm{N}}\right)$

This motion is $\mathrm{P}^{+}$-stable as it represents the column behavior under ideal inventory control (Shinskey, 1977): the output composition is maintained constant by balancing the energy and mass delivered to the system against the demand of the load. The stability of this motion in the presence of the fast unmodelled hydraulic dynamics follows from standard arguments in singular perturbation theory for dynamical systems (Khalil, 2002). The combination of the zerodynamics with its associated material balance SF controller yields the optimal FF controller

$$
\begin{array}{ll}
\dot{\hat{x}}=\mathrm{f}\left[\hat{\mathrm{x}}, \mu_{\mathrm{R}}\left(\hat{\mathrm{x}}, \overline{\mathrm{c}}_{\mathrm{p}}\right)\right], & \hat{\mathrm{x}}\left(\mathrm{t}_{\mathrm{o}}\right)=\hat{\mathrm{x}}_{\mathrm{o}}, \quad \mathrm{t} \in\left[\mathrm{t}_{\mathrm{o}}, \mathrm{t}_{\mathrm{f}}\right] \quad(10) \\
\mathrm{t}_{\mathrm{s}}=\mu_{\mathrm{s}}(\hat{\mathrm{x}}), & \mathrm{t}_{\mathrm{f}}=\mu_{\mathrm{f}}(\hat{\mathrm{x}}) \\
\mathrm{u}=\mu_{\mathrm{R}}\left(\hat{\mathrm{x}}, \overline{\mathrm{c}}_{\mathrm{p}}\right), & \mathrm{c}_{\mathrm{N}}\left(\mathrm{t}_{\mathrm{s}}\right)=\overline{\mathrm{c}}_{\mathrm{N}}=\mathrm{E}^{-1}\left(\overline{\mathrm{c}}_{\mathrm{p}}\right), \quad \mathrm{t}_{\mathrm{s}}<\mathrm{t} \leq \mathrm{t}_{\mathrm{f}}
\end{array}
$$

The closed-loop column motion $\mathrm{P}^{+}$-stability follows from the same property of the reduced column system (4) and the hydraulic dynamics fastness:

Proposition 1. For any load composition $\mathrm{c}_{\mathrm{F}} \in \mathrm{C}_{\mathrm{F}}$ the optimal column controlled motion (9), is passive, or equivalently,

i) The system input-output pair $\left(\mathrm{u}, \mathrm{z}=\mathrm{c}_{\mathrm{N}}\right)$ has relative degree equal to one because of the fulfillment of the next conditions

$\mathrm{R}<\mathrm{V}^{+}, \quad \mathrm{E}^{\prime}\left(\overline{\mathrm{c}}_{\mathrm{P}}\right)>1, \quad \mathrm{~m}_{\mathrm{P}}>0$ 
ii) The zero-dynamics motion $\mathrm{x}_{\mathrm{I}}(\mathrm{t})$ is $\mathrm{P}^{+}$-stable.

iii) The application of the FF (10) and SF (8) passive material balance controllers to the column with hydraulic dynamics (3) yields a $\mathrm{P}^{+}$-stable closed-loop motion (9).

The behavior of the nonlinear SF material-balance controller (8) represents the behavior attainable with any observer-based passive OF controller, and such behavior will be considered the recovery target for the next OF control design.

\section{OUTPUT FEEDBACK CONTROL}

\subsection{State estimation and sensor allocation}

By design specification, the preceding $\mathrm{u}_{\mathrm{R}}=\mathrm{R}-\mathrm{to}_{\mathrm{z}} \mathrm{z}=$ $\mathrm{c}_{\mathrm{N}}$ passive controller must be implemented with a $\mathbf{l -}$ to-y passive state estimator, with 1 representing the unknown input that is reconstructed to eliminate the output prediction mismatch (Alvarez and López, 1999; Lopez and Alvarez, 2004). In the general multi-sensor case, the corresponding distillation column passive estimator is given by:

$$
\begin{aligned}
& \dot{\hat{\imath}}=\mathrm{K}\left(\hat{\mathrm{x}}_{\mathrm{l}}\right)[\mathrm{y}(\mathrm{t})-\mathrm{h}(\hat{\mathrm{x}})], \hat{\mathrm{\imath}}\left(\mathrm{t}_{\mathrm{o}}\right)=0, \mathrm{l}=\left(\mathrm{t}_{1}, \ldots, \mathrm{t}_{\mathrm{m}}\right)^{\prime} \\
& \dot{\hat{x}}_{l}=\mathrm{f}_{\mathrm{l}}\left[\hat{\mathrm{x}}_{\mathrm{l}}, \hat{\mathrm{x}}_{\mathrm{v}}, \mathrm{u}_{\mathrm{R}}(\mathrm{t})\right]+\mathrm{G}\left(\hat{\mathrm{x}}_{\mathrm{l}}\right)\left[\mathrm{y}-\mathrm{h}\left(\hat{\mathrm{x}}_{\mathrm{l}}\right)\right]+\hat{\mathrm{t}}, \hat{\mathrm{x}}_{\mathrm{l}}(0)=\hat{\mathrm{x}}_{\mathrm{l}} \\
& \hat{\mathrm{x}}_{\mathrm{v}}=\mathrm{f}_{\mathrm{v}}\left[\hat{\mathrm{x}}_{\mathrm{l}}, \hat{\mathrm{x}}_{\mathrm{v}}, \mathrm{u}_{\mathrm{R}}(\mathrm{t})\right], \hat{\mathrm{x}}_{\mathrm{v}}(0)=\hat{\mathrm{x}}_{\mathrm{v}_{\mathrm{o}}}, \hat{\mathrm{x}}_{\mathrm{t}}=\left(\hat{\mathrm{c}}_{\mathrm{s}_{1}}, \ldots, \hat{\mathrm{c}}_{\mathrm{s}_{\mathrm{T}}}\right)^{\prime} \\
& \left(\hat{\mathrm{x}}_{\mathrm{v}}^{\prime}, \hat{\mathrm{x}}_{\mathrm{v}}^{\prime}\right)^{\prime}=\mathrm{I}_{\mathrm{p}} \hat{\mathrm{x}}, \quad\left(\mathrm{f}_{\mathrm{t}}^{\prime}, \mathrm{f}_{\mathrm{v}}^{\prime}\right)^{\prime}=\mathrm{I}_{\mathrm{p}} \mathrm{f}, \quad \omega=\min \left(\omega_{1}, \ldots, \omega_{\mathrm{m}}\right) \\
& \mathrm{G}\left(\hat{\mathrm{x}}_{\mathrm{l}}\right)=2 \operatorname{diag}\left[\zeta_{1} \omega_{1} / \beta^{\prime}\left(\hat{\mathrm{c}}_{\mathrm{s}_{1}}\right), \ldots, \zeta_{\mathrm{m}} \omega_{\mathrm{m}} / \beta^{\prime}\left(\hat{\mathrm{c}}_{\mathrm{s}_{\mathrm{m}}}\right)\right] \\
& \mathrm{K}\left(\hat{\mathrm{x}}_{\mathrm{l}}\right)=\operatorname{diag}\left[\omega_{1}^{2} / \beta^{\prime}\left(\hat{\mathrm{c}}_{\mathrm{s}_{1}}\right), \ldots, \omega_{\mathrm{m}}^{2} / \beta^{\prime}\left(\hat{\mathrm{c}}_{\mathrm{s}_{\mathrm{m}}}\right)\right] \text {, }
\end{aligned}
$$

where $\mathrm{x}_{1}$ (or $\mathrm{x}_{v}$ ) is the innovated (or non-innovated) state, in the sense that measurement innovation is (or is not) injected to its state dynamics, and $\hat{\imath}$ compensates the modeling error to eliminate the output mismatch, $\omega_{\mathrm{i}}$ (or $\zeta_{\mathrm{i}}$ ) is the characteristic frequency (or damping factor) of the almost (linear non-interactive pole assignable) i-th output error dynamics, $I_{p}$ is a column-permuted identity matrix, and $\mathrm{G}$ and $\mathrm{K}$ are gain matrices. The functioning of the above estimator requires the adequate fulfilment of two conditions (Lopez et al, 2004):

(i) The column motion $\mathrm{x}(\mathrm{t})$ must be partially observable with passive structure, this is, $\forall \mathrm{t} \in\left[\mathrm{t}_{\mathrm{o}}, \mathrm{t}_{\mathrm{f}}\right]$ $\operatorname{rank} \mathrm{G}\left[\mathrm{x}_{\mathrm{t}}(\mathrm{t})\right]=\mathrm{m} \Leftrightarrow \beta^{\prime}\left(\hat{\mathrm{c}}_{\mathrm{s}_{\mathrm{i}}}\right) \neq 0, \mathrm{i}=1, \ldots, \mathrm{n}_{\mathrm{T}}$

(ii) The non-innovated motion must be $\mathrm{P}^{+}$-stable:

$\mathrm{x}_{\mathrm{v}}(\mathrm{t})=\tau_{\mathrm{I}}\left[\mathrm{t}, \mathrm{t}_{\mathrm{o}}, \mathrm{x}_{\mathrm{vo}}, \mathrm{x}_{\mathrm{l}}(\cdot)\right], \quad \mathrm{x}_{\mathrm{l}}(\mathrm{t})=\mathrm{h}^{-1}[\mathrm{y}(\mathrm{t})]$

$\mathrm{x}_{v}(\mathrm{t})$ is the solution of Eq. (12b) with $\mathrm{x}_{\mathrm{l}}(\mathrm{t})=\mathrm{h}^{-1}[\mathrm{y}(\mathrm{t})]$ and $\hat{x}_{v}(0)=x_{v_{o}}$, and its $\mathrm{P}^{+}$-stability follows from the $\mathrm{P}^{+}$-stability of the open or closed-loop column motion. The adequate fulfilment of these conditions (13) signify that the column motion is robustly detectable with passive structure, provided none of the sensors is at a tray with closed-to azeotropic or high-purity composition, implying the estimator functioning with a reasonable compromise between reconstruction rate and robustness. Typically, the estimator must be tuned from 3 to 10 times slower than the hydraulics. A nonlinear time-varying robust detectability-based criterion for choosing the measurement structure for estimation purposes (López et. al, 2004), in conjunction with previous measurement structure selection studies for staged processes (Romagnoli et. al, 1981), lead to the conclusions:

(i) The measurement error propagation assessment should be started by looking at the following individual sensor $\left(\mathrm{y}_{\mathrm{i}}=\mathrm{c}_{\mathrm{i}}\right)$ error propagation measure over location and time:

$\kappa(\mathrm{i}, \mathrm{t})=\left|1 / \beta^{\prime}\left[\hat{\mathrm{c}}_{\mathrm{i}}(\mathrm{t})\right]\right|<\infty, \mathrm{i} \in\{0,1, \ldots, \mathrm{N}\}, \mathrm{t} \in\left[0, \mathrm{t}_{\mathrm{f}}\right]$

(ii) A single sensor must be located in the reboiler, where the tray-to-tray temperature gradient is maximum, or equivalently, the error propagation measure $\kappa(\mathrm{i}, \mathrm{t})(14)$ is minimum, and this is in agreement with previous sensor location criteria for distillation column control purposes (Tolliver et. al, 1980; Castellanos et. al, 2005a). As the temperature measurement is moved upwards, the error propagation grows, and this should happen rapidly in a high-purity column like the one that will be addressed in the application example section.

(iii) In the multi-sensor case, the best set with $\mathrm{m}$ sensors consists of the union of the $\mathrm{m}$ best individual sensors and this is in agreement with previous reports (Alvarez et. al, 1981).

(iv) Choose a candidate m-sensor location set, and ratify or rectify the result by estimator implementation and testing.

\subsection{Output-feedback control}

The combination of the SF controller (8) with the estimator (13) yields the OF controller (Figure 1):

$$
\begin{aligned}
& \dot{\hat{\imath}}=\mathrm{K}\left(\hat{\mathrm{x}}_{\mathrm{t}}\right)[\mathrm{y}(\mathrm{t})-\mathrm{h}(\hat{\mathrm{x}})], \quad \hat{\mathrm{t}}\left(\mathrm{t}_{\mathrm{o}}\right)=0 \\
& \hat{\mathrm{x}}_{\mathrm{l}}=\mathrm{f}_{\mathrm{l}}\left[\hat{\mathrm{x}}_{\mathrm{l}}, \hat{\mathrm{x}}_{\mathrm{v}}, \mathrm{u}_{\mathrm{R}}(\mathrm{t})\right]+\mathrm{G}\left(\hat{\mathrm{x}}_{\mathrm{l}}\right)\left[\mathrm{y}-\mathrm{h}\left(\hat{\mathrm{x}}_{\mathrm{l}}\right)\right]+\hat{\mathrm{t}}, \hat{\mathrm{x}}_{\mathrm{l}}(0)=\hat{\mathrm{x}}_{\mathrm{o}} \\
& \hat{\mathrm{x}}_{\mathrm{v}}=\mathrm{f}_{\mathrm{v}}\left[\hat{\mathrm{x}}_{\mathrm{l}}, \hat{\mathrm{x}}_{\mathrm{v}}, \mathrm{u}_{\mathrm{R}}(\mathrm{t})\right], \quad \hat{\mathrm{x}}_{\mathrm{v}}(0)=\hat{\mathrm{x}}_{\mathrm{v}_{\mathrm{o}}} \\
& \mathrm{u}=\mu\left(\mathrm{x}, \overline{\mathrm{c}}_{\mathrm{p}}\right): \mathrm{u}=\mathrm{V}, \mathrm{t}_{\mathrm{o}} \leq \mathrm{t} \leq \mathrm{t}_{\mathrm{s}} ; \mathrm{u}=\mu_{\mathrm{R}}\left(\mathrm{x}, \overline{\mathrm{c}}_{\mathrm{p}}\right), \mathrm{t}_{\mathrm{s}}<\mathrm{t} \leq \mathrm{t}_{\mathrm{f}}
\end{aligned}
$$

in IMC form. The rigorous verification of the related closed-loop stability conditions goes beyond the scope of the present work, and here it suffices to state the result in the next proposition, in the understanding that the proof follows from the application of the standard singular perturbation method (Alvarez et. al., 2004b) and the afore stated definitions of $\mathrm{P}^{+}$and $\mathrm{P}^{-}$batch motion stability.

Proposition 2. The OF controller (15) yields an optimal closed-loop batch column operation with with $\mathrm{P}^{+}$-stable state motion $\mathrm{x}(\mathrm{t})$ and $\mathrm{P}^{-}$-stable product composition trajectory $\mathrm{c}_{\mathrm{p}}(\mathrm{t})$ :

$\mathrm{c}_{\mathrm{P}}(\mathrm{t}) \rightarrow \overline{\mathrm{c}}_{\mathrm{P}},\left|\mathrm{c}_{\mathrm{P}}\left(\mathrm{t}_{\mathrm{f}}\right)-\overline{\mathrm{c}}_{\mathrm{P}}\right| \leq \varepsilon_{\mathrm{p}} ; \mathrm{J}(\mathrm{t}) \rightarrow \overline{\mathrm{J}}(\mathrm{t}),\left|\dot{\mathrm{J}}\left(\mathrm{t}_{\mathrm{f}}\right)\right| \leq \varepsilon_{\mathrm{J}}(\mathrm{a}-\mathrm{b})$

if the estimator (15) is tuned so that

$\omega^{-} \leq \omega=\min \left(\omega_{\mathrm{i}}, \omega_{\mathrm{j}}\right) \leq \omega^{+}\left(\lambda_{\mathrm{m}}, \lambda_{\mathrm{c}}\right), \quad \partial_{\lambda \mathrm{m}} \omega^{+}>0$ $\omega \approx \lambda_{\mathrm{m}} / \mathrm{n}_{\mathrm{o}}, \mathrm{n}_{\mathrm{o}} \approx 3$ to 10 


\section{APPLICATION EXAMPLE}

Case example. Let us recall an ethanol-water batch distillation column studied before (Barolo et. al, 1998, Alvarez et. al, 2004a). There are $\mathrm{N}=8$ trays, the initial load is $\mathrm{m}_{\mathrm{L}}=8000 \mathrm{~mol}$ at composition $\mathrm{c}_{\mathrm{F}}=$ 0.40 , the vapor flow is $\mathrm{V}=5400 \mathrm{~mol} / \mathrm{h}$, the tray hydraulic parameter set is $\left(\lambda_{\mathrm{m}}, \mathrm{a}, \mathrm{b}\right)=\left(1000 \mathrm{~h}^{-1}\right.$, $5400,30)$, the condenser holdup is $\mathrm{m}_{\mathrm{D}}=250 \mathrm{~mol}$, and the nominal product composition is $\bar{c}_{p}=0.84$. The constants of the objective function (1) are: $\left(\mathrm{C}_{\mathrm{p}}\right.$, $\left.\mathrm{C}_{\mathrm{L}}\right)=(50,5) \$ / \mathrm{mol},\left(\mathrm{C}_{\mathrm{h}}, \mathrm{C}_{\mathrm{c}}\right)=(1,1) 2 \times 10^{-6} \$ / \mathrm{kJ}, \mathrm{C}_{\mathrm{O}}$ $=3 \$ / \mathrm{h},\left(\lambda_{\mathrm{V}}, \lambda_{\mathrm{R}}\right)=(3.96,3) \times 10^{4} \mathrm{~kJ} / \mathrm{mol}, \mathrm{t}_{\mathrm{d}}=0.5 \mathrm{~h}$.

By nominal (or robust) operation we will understand the optimal closed-loop batch column operation with "central" (or perturbed) load concentration $\mathrm{c}_{\mathrm{F}}=0.40$ (or $\mathrm{c}_{\mathrm{F}} \in \mathrm{C}_{\mathrm{F}}$ deviated), actual (or erroneous) estimate $\hat{\mathrm{c}}_{\mathrm{F}}$, and noiseless (or noisy) measurements. In the noisy measurement case, Gaussian (zero-mean and $0.1 \mathrm{~K} \mathrm{SD}$ ) random errors, will be added every 0.16 $\mathrm{min}$, and the estimator will be initialized with $+10 \%$ load composition error. Following the tuning guidelines given in Section 4, the following estimator (15) gain parameters were chosen: $\zeta=2.0, \omega_{\mathrm{i}}=$ $\lambda_{\mathrm{m}} /(4 \mathrm{~N})$ (i.e., 4 times slower than the one of the hydraulics).

Nominal operation. The application of the proposed design procedure (12) yields the optimal (exact FF or $\mathrm{SF}$ ) operation (4a) shown in Figure 2, with $\left(\mathrm{t}_{\mathrm{s}}, \mathrm{t}_{\mathrm{f}}\right)=$ $(0.45,3.7) \mathrm{h}$, which basically coincides with the ones drawn before via standard open-loop optimization techniques (Li et. al, 2001).

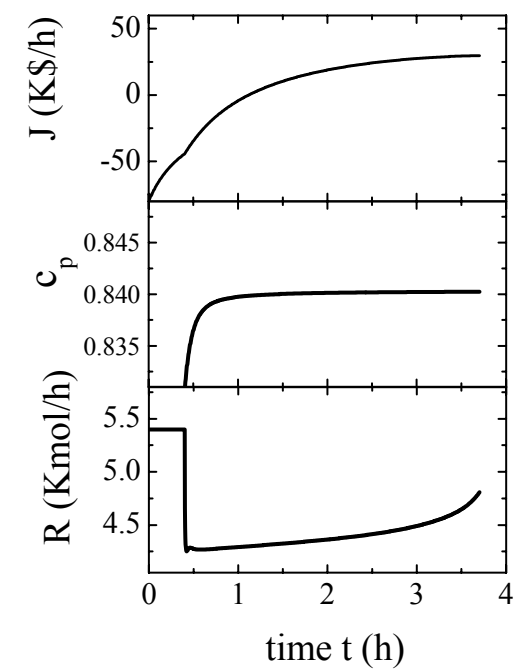

Fig. 2. Nominal optimal operation with $\mathrm{c}_{\mathrm{F}}=0.4$.

Measurement structure. Following the measurement selection guidelines of Section 4, the error propagation dependency function $\kappa(i, t)(14)$ (shown in Figure 3) was analyzed, finding that: (i) the best (or worst) location corresponds to the reboiler (or Nth tray), (ii) above the $3^{\text {rd }}$-tray the error propagation measure is quite large, (iii) there should be at most two sensors in the bottom region, and the reboiler must be included.

Robust operation. Figure 4 shows the column robust behavior in the presence of measurement noise, for two single-sensor locations and nominal load composition $\mathrm{c}_{\mathrm{F}}=0.4$ : the reboiler $\left(\mathrm{s}_{\mathrm{n}_{1}}=0\right.$ ), and the 4th tray $\left(s_{n_{1}}=4\right)$. As expected, the reboiler sensor outperforms the 4-th tray one.

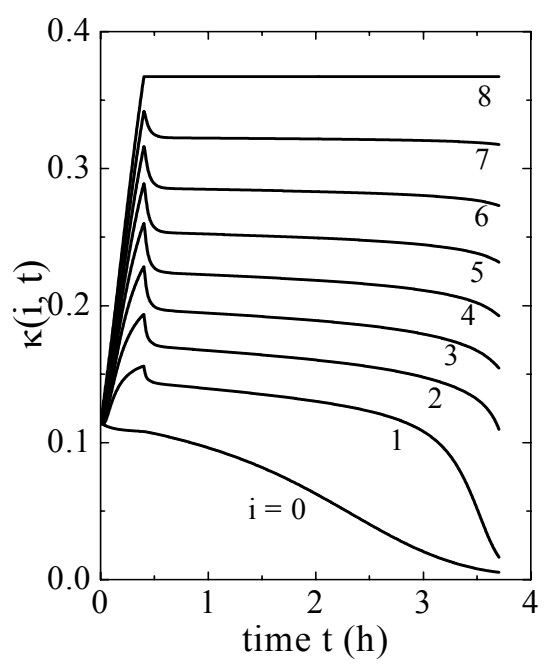

Fig. 3. Error propagation measure dependency $\kappa(\mathrm{i}, \mathrm{t})$ on location stage (i) and time (t).

Sensor pairs in the bottom region were tried, including the reboiler. It was found that: (i) only the reboiler-first tray pair slightly improved the behavior of the reboiler sensor alone, and (ii) all the other pairs yielded worst behaviours. Thus, the reboiler sensor yielded the best compromise between simplicity, performance and robustness. These results differ from the ones drawn when the study is performed in the absence of hydraulic dynamics and measurement noise (Alvarez et. al., 2004a). Figure 5 shows the robust column behavior, for various load concentrations $(0.2,0.3,0.4,0.5,0.6)$ and using only the reboiler temperature measurement. As it can be seen in the figure, the on-line optimizing capability of the control scheme adjusts the switching time, the batch duration, and the reflux policy so that the utility function always ends up at its maximum value.

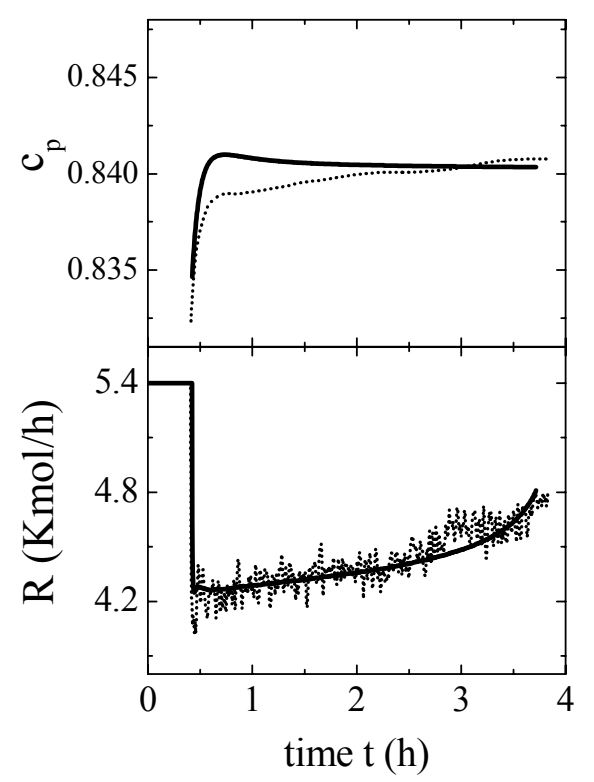

Fig. 4. Closed loop robust behavior with one temperature measurement at: reboiler $(-)$, and 4 th tray $(\cdots)$. 


\section{CONCLUSIONS}

The problem of designing an optimal robust OF controller for binary batch distillation columns has been addressed, by combining optimality, passivity and detectability notions and tools. The proposed methodology has: solvability conditions with physical meaning, a systematic control construction with a simple tuning scheme coupled to a closedloop stability criterion. From the control and estimator robustness-oriented passivity requirements, it followed that the $\mathrm{N}$-th tray composition should be regulated on the basis of an estimator-based material balance driven by the reboiler temperature measurement. The approach is applied to an early studied (Barolo et. al, 1998, Alvarez et. al, 2004a) simulated example, finding that the proposed control scheme effectively handles the case of large load composition disturbances in conjunction with measurement noise and the presence of the hydraulic dynamics. It was verified that unmeasured outputdriven feedback does not improve the behavior of the observer-based material balance controller. The behavior limiting roles of the hydraulic dynamics and measurement noise were verified, signifying that the optimal motion and control design study should be performed and tested within a robustness framework. The extension of the proposed approach to the case of thermodynamic model uncertainties within a batch-to-batch operation framework is being pursued.

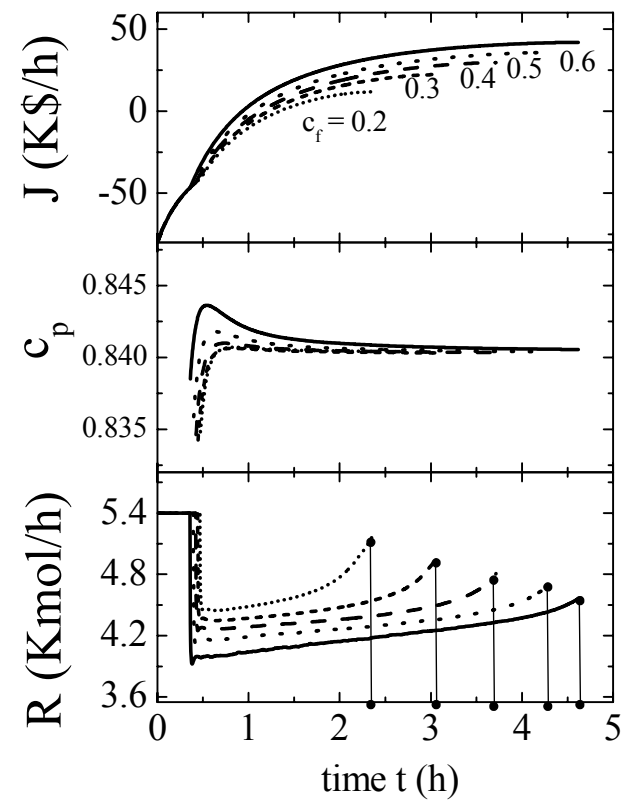

Fig. 5. Closed loop robust behavior for various load compositions, with (-10\%) load composition estimation error, and one noisy measurement at the reboiler.

\section{REFERENCES}

Alvarez, J., Castellanos-Sahagún, E., Fernández, C., Aguirre, S. (2004a). Joint operation and control design for binary batch distillation columns. Symp. on Knowledge Driven Batch Processes, BATCHPRO 2004, Greece, pp. 211-218.
Alvarez, J., Lopez, T. (1999), Robust dynamic state estimation of nonlinear plants. AIChE J. 45(1), pp. 107-118.

Alvarez, J., Romagnoli, J., A., Stephanopoulos, G., (1981) Variable measurement structures for the control of a tubular reactor Chem. Eng. Sci. 36(10) pp 1695-1712.

Alvarez, J., Zaldo, F., Oaxaca, G. (2004b), “Towards a joint process and control design for batch processes: application to semibatch polymer reactors". In: Integration of Process and Control (Ed. Georgiadis, M. Seferlis, P.), Elsevier.

Barolo, M., Berto, F. (1998). Compositioin control in batch distillation: binary and multicomponent mixtures Ind. Eng. Chem. Res., 37, pp. 46894698.

Bosley, J. R. Edgar, T. (1992). Application of nonlinear model predictive control to optimal batch distillation. $3^{\text {rd }}$ IFAC Symposium DYCORD'92, pp. 271-276.

Castellanos-Sahagún, E., Alvarez, J. (2005a). Twopoint temperature control structure and algorithm design for binary distillation columns. Ind. Eng. Chem. Res. (44), pp. 142-152.

Castellanos-Sahagún, E., Alvarez, J. (2005b). Synthesis of two-point controllers for binary distillation columns. To appear in Chem. Eng. Comm.

Finefrock, Q. B., Bosley, J. R. Edgar, T. (1994). Gain scheduled PID control of batch distillation to overcome changing system dynamics. AIChE Annual Mtng, San Francisco, 1994.

Khalil, H. K. (2002). Nonlinear Systems, $3^{\text {rd }}$ Ed. Prentice-Hall, Upper Saddle River, NJ.

La Salle, J. Lefschetz, S. (1961). Stability by Lyapunov's Direct Method, Academic Press, NY.

Lopez, T., Alvarez, J. (2004), On the effect of the estimation structure in the functioning of a nonlinear copolymer reactor estimator. J. Proc. Contr., 14(1) pp. 99-109.

Muhrer, C. A. Luyben, W. (1992). Batch Distillation. In W. L. Luyben (Ed.), Practical Distillation Control, pp. 508-528. NY, Van Nostrand Reinhold.

Mujtaba, I. M., Macchieto, S. (1996). Simultaneous optimization of design and operation of multicomponent batch distillation column-single and multiple separation duties. J. Proc. Cont. 6(1), pp. 27-36.

Shinskey, F. G. (1977), Process Control Systems, $2^{\text {nd }}$ Ed. McGraw-Hill.

Sontag, E. D. (2000). The ISS philosophy as a unifying framework for stability-like behavior. In: Nonlinear Control in the Year 2000 (Vol. 2). A. Isidori, F. Lamnabhi-Lagarrigue, W. Respondek, (Editors). Springer-Verlag, Berlin.

Tolliver, T. L., McCune, L. C. (1980). Finding the optimum temperature control trays for distillation columns. InTech 27(9), 75. 